\title{
Why is physical education more stimulating for pupils who are more satisfied with their own body?
}

Charlotte Kerner ${ }^{\mathrm{a}}$, David Kirk ${ }^{\mathrm{b}}$ An De Meester ${ }^{\mathrm{c}}$ Leen Haerens $^{\mathrm{c}}$

a Department of Life Sciences, Division of Sport and Exercise Sciences, Brunel University London, UK

${ }^{\mathrm{b}}$ School of Education, University of Strathclyde, Glasgow, UK

'Department of Movement and Sports Sciences, Ghent University, Ghent, Belgium.

\begin{abstract}
Objective: This study explored whether pupils' state body satisfaction during physical education related to the degree to which they indicated that physical education stimulated them to engage in sports activities outside of school. It also investigated whether pupils' self-determined motivation mediated this relationship, such that pupils with higher body satisfaction were more likely to value and enjoy the lessons, and to indicate they would reengage in the activities outside of physical education.
\end{abstract}

Methods: The study included 506 13-14-year-old pupils (51.19\% girls) from the UK, who completed validated questionnaires to measure perceived body satisfaction, motivation for physical education, and the perceived sport promoting role of physical education.

Results: Results showed that body satisfaction positively related to the perceived sport promoting role of physical education in girls. The relationship between stated body satisfaction during physical education and the perceived sport promoting role of physical education was partially mediated by pupils' self-determined motivation.

Conclusions: Pupils who felt more comfortable and satisfied with their physical appearance, seemed to value and enjoy physical lessons more, and this more positive experience stimulated them to re-engage in the activities outside school.

Keywords: body satisfaction, self-determination theory, motivation, physical education, physical activity, pupils, UK

\section{Corresponding author}

Charlotte Kerner, Department of Life Sciences, Division of Sport and Exercise Sciences, Brunel University London, Kingston Lane, London, UB8 3PH, UK

Email: Charlotte.kerner@brunel.ac.uk 


\section{Introduction}

An impressive body of literature has shown that sufficient levels of moderate-to-vigorous physical activity during childhood and adolescence are associated with physical, psychological and social health benefits in the short- and longer-term (e.g. Janssen and LeBlanc, 2010). Yet, a large number of studies show that the majority of children and adolescents do not meet the current international recommendation of at least $60 \mathrm{~min}$ of moderate-to-vigorous physical activity per day (Ekelund, Tomkinson and Armstrong, 2011). Furthermore, the decline in physical activity levels increases with age, with a steep decline occurring during the transition from childhood to adolescence (Corder et al., 2015). One of the reasons for this decline is that sports participation peaks when children are 11-13 years old and then declines through adolescence (Zimmermann-Sloutskis et al., 2010). Because physical education is considered an important vehicle to promote enduring participation in sport (especially during adolescence) (Shephard and Trudeau, 2000; Haerens et al., 2010), it is essential to gain more insight into the physical education related factors that effectively stimulate young people to engage in sport beyond the school day.

Given that the body lies at the centre of the learning process in physical education, pupils learning experiences in physical education are likely to be influenced by their perceptions of their body (Kerner et al., 2018). Pupils' body (dis-)satisfaction is thus one crucial factor that influences how pupils experience physical education lessons and, in turn, whether they experience the lesson as stimulating. While positive links have been established between body satisfaction and participation in overall physical activity (Kantanista et al., 2015), and between social physique anxiety and motivation for physical activity more generally (Brunet and Sabiston, 2009, Cox et al., 2011), few, if any studies have investigated if and how experiences of body satisfaction during physical education relate to the sport promoting role of physical education. Moreover, the mechanisms underlying this relationship (i.e. the role of motivation) have not received attention so far. Understanding these processes allows for the development of pedagogy to support the sport promoting role of physical education.

\section{Body satisfaction and physical activity participation}

Body satisfaction is the attitudinal component of the body image construct that focuses on satisfaction or dissatisfaction with the physical appearance or the body (Thompson, 2004). Body image has been related to physical activity participation more generally (Kantanista et al., 2015) and engagement in physical education in particular (Carmona et al., 2015). With regards to the nature of the relationship between body satisfaction and overall physical activity participation, results are inconclusive. For example, in adults some evidence suggests significant positive associations between body image and physical activity participation (Wetterhahn et al., 2002). However, other studies have identified that body image is unrelated to objective physical activity in women undergraduates (Rote et al., 2013). Among adolescents, some evidence suggests that boys and girls categorised as having low body satisfaction engage in less activity and spend more time in sedentary pursuits compared to those categorised as having high body satisfaction (Neumark-Sztainer et al., 2004). Furthermore, body satisfaction was found to relate positively to moderate to vigorous physical activity in adolescents (Kantanista et al., 2015) with longitudinal 
explorations noting similar outcomes (Neumark-Sztainer et al., 2006). However, in other studies with 11-14 years old boys and girls from the UK (Duncan et al., 2004), and high school aged girls from the USA (Neumark-Sztainer et al., 2003) non-significant relationships have been found between body image and physical activity outcomes. To our knowledge, there is only one study so far that has taken place in the context of physical education. This study was based in the USA and showed that enhanced body image positively impacted physical activity levels by increasing pupils' engagement in physical education (Bevans et al., 2010).

All of the above studies focus on trait aspects of body image (i.e. body dissatisfaction as a stable and unchanging characteristic). However, when there is a need to better understand mechanisms in relation to a specific context such as the physical education lesson, the importance of exploring body image from a state perspective has been advocated (Cash et al., 2002). State body satisfaction relates to an individual's feelings about their body, at a particular moment in time, within a particular context. Building on the emerging body of literature on the physical education context, the current study explores how state body satisfaction during a specific physical education lesson relates to the sport promoting role of physical education. Grounded in self-determination theory (Deci and Ryan, 2012), we aimed to investigate whether pupils' motivation intervenes in the relationship between experienced body satisfaction and physical education's sports promoting role.

\section{Self Determination Theory}

Self-determination theory (SDT) is a macro-theory of human motivation, which allows for an understanding of the initiation and maintenance of behaviours (Deci and Ryan, 2012). It has been previously used to understand the sport promoting role of physical education (Haerens et al., 2010). The theory suggests that the type of motivation is of greater importance than the quantity of motivation in explaining human actions (Deci and Ryan, 2000). Behaviours can be represented along a self-determination continuum, ranging from higher to lower levels of self-determination, depending on the extent to which the behaviour is volitional. Six different types of motivation exist along the continuum, which can further grouped into autonomous motivation, controlled motivation and amotivation (Haerens et al., 2010). Autonomous motivation is the most self-determined and combines intrinsic motivation (undertaking an activity for the inherent pleasure of and interest in the activity itself), integrated regulation (undertaking an activity because it fits the different goals and values you have in life), and identified regulation (when the outcome of the behaviour is personally important) (Ryan and Deci, 2007). Controlled motivation combines introjected regulation (an individual engages in a behaviour to avoid guilt or obtain social approval) and external regulation (an individual engages in a behaviour to avoid punishment or obtain a reward) (Ryan and Deci, 2007). Autonomous motivation is based on values or personal interests, whereas, controlled motivation is based on demands that are either externally or internally imposed (Van den Berghe et al., 2014). Amotivation is at the end of the continuum and is evident when an individual is neither intrinsically nor extrinsically motivated, thus, lacks motivation and volition (Deci and Ryan, 1985).

Different studies have shown that the quality of pupils' motivation for physical education matters in relation to physical activity and sport promotion among adolescents. 
Autonomous motivation for physical education positively relates to objectively measured physical activity within the physical education lesson (Aelterman et al., 2012), intentions to be physically active beyond the school (e.g. Chatzisarantis and Hagger, 2009; Sanchez-Olivia et al., 2014), and objectively measured leisure time physical activity (Owen et al., 2013). With regard to the sport promoting role of physical education, a retrospective study of university students revealed that students who were mainly autonomously motivated for physical education were more likely to report that physical education had stimulated them to engage in sports activities outside school, while the opposite was true of highly controlled or amotivated students (Haerens et al., 2010). In their transcontextual model, Hagger and colleagues (2009) provide an explanation for these findings, by revealing that autonomous motivation towards physical education generalises to autonomous motivation for leisure time physical activity, and in turn to higher levels of physical activity in leisure time.

\section{Body satisfaction, motivation and sport promotion}

An individual's body satisfaction is likely to relate to their motivation to participate in physical activity and physical education. For example, if someone is more dissatisfied with their body they may be more likely to internalise pressure to be active (i.e. controlled motivation), specifically they may feel more ashamed (i.e. introjected regulation) or worry more about the opinions of others (i.e. external regulation). This is supported by evidence that suggests young people with greater body concerns experience more extrinsic physical activity goals and subsequently less self-determined forms of physical activity motivation (Gillion et al., 2006). This is also supported in physical education, in which lower social physique anxiety has been associated with higher levels of autonomous motivation and lower amotivation (Cox et al., 2011). Few studies have explored the mediating role of the quality of students' motivation in the relationship between body satisfaction and physical activity behaviours in adolescents. The few available studies have focused on motivation in the relation between social physique anxiety and physical activity outcomes (Gillison et al., 2006; Cox et al., 2011; Sicilia et al., 2016). Social physique anxiety can be aligned with a negative body image perspective, which traditionally focuses on pathology and alleviating body image symptoms (Tylka and Wood-Barcalow, 2015). Social physique anxiety, for instance, refers to the anxiety that individuals experience at the prospect of others evaluating their physique (Hart et al., 1989). The findings on social physique anxiety are mixed. For example, the mediating role of individual motivation regulations (autonomous motivation, introjected regulation, external regulation and amotivation) in the relationship between social physique anxiety and physical education participation was not supported by Cox et al., (2011). However, the mediating role of intrinsic, integrated and identified motivation in the relationship between social physique anxiety exercise behaviour and physical activity intentions in adolescents has been supported elsewhere (Sicilia et al., 2016). To our knowledge, there are no studies that have explored this relationship using state body satisfaction. Adopting a state body satisfaction approach reflects wider trends within the academic literature to focus on body image from a positive perspective. A positive body image approach focuses on the promotion of a positive body image, hereby allowing individuals to appreciate and celebrate their bodies (Tylka and Wood-Barcalow, 2015).

\section{The present study}


The purpose of the present study was threefold. First, the study sought to describe pupils' perceptions of the extent to which physical education stimulated them to engage in sports activities outside of school. In line with the findings of the retrospective experiences of university students (Haerens et al., 2010), it was expected that a substantial proportion of pupils will report that physical education did not stimulate them to engage in physical activity outside of school. Furthermore, due to identified sex differences in physical education experiences (e.g. Cairney et al., 2012) it was expected that boys will respond more positively to the sport promoting role than girls.

Secondly, the study investigated whether state body satisfaction during the physical education lesson was associated with the experienced the sports promoting role of physical education. It was expected that both boys and girls who reported higher state body satisfaction would also more strongly agree that physical education stimulated them to engage in sports activities beyond the school. Support for this hypothesis would be consistent with research that suggests body satisfaction can predict physical activity in adolescents (Kantanista et al., 2015).

Finally, if state body satisfaction during physical education is an important factor in relation to physical educations' sport promoting role, it would be consistent with the findings of Brunet and Sabiston (2009) that pupils' self-determined motivation will mediate this relationship. It was expected that higher levels of body satisfaction will be associated with more autonomous motivation, less controlled motivation and less amotivation, and in turn with pupils stating more strongly that physical education stimulated them to engage in sports outside school. We hypothesise that this will be the case because pupils who feel more satisfied with their bodies will also be more likely to value and enjoy the activity at hand (i.e. autonomous motivation), and will therefore be more likely to re-engage in this activity in their leisure time.

\section{Methods}

\section{Participants and Procedures}

Schools were recruited using a purposive sampling strategy. Ten local co-educational schools, based in the south-east of England were contacted through email and invited to participate in the study. The schools were contacted using the email address of each physical education head of department that was sourced through the webpages of the respective schools. Four schools positively responded to this email invitation and meetings were conducted with the teachers at each school to discuss the study details and confirm participation. After the four schools had agreed to take part, all pupils and parents/carers within each year 9 physical education class were provided with an information sheet that outlined the requirements of the study. They were invited to participate through passive consent procedures, in which parents/carers and pupils could retract participation. Ethical approval was obtained from the lead authors research committee.

Through the passive consent procedures, seven pupils retracted participation. The final sample consisted of 506 participants ( $51.19 \%$ girls, $48.8 \%$ boys) from 37 year nine (aged 13 - 
14) physical education classes. The physical education classes were taught by 13 teachers ( 6 male, 7 female). Each class participated in two lessons of physical education a week.

Pupils completed a paper and pencil questionnaire package during one physical education lesson. The questionnaire took approximately 20 minutes to complete. Pupils were instructed to respond to all items on the questionnaires. Pupils were supervised by the first author and the class teacher throughout the process, both of whom were available to clarify instructions and provide support for comprehension.

\section{Measures}

\section{Motivation for Physical Education}

To assess motivation to put effort into physical education, pupils completed the Behavioral Regulations in Physical Education Questionnaire (BRPEQ) (Aelterman et al., 2012). This questionnaire was adapted by Aelterman et al., (2012) from the Behavioural Regulation in Exercise Questionnaire (BREQ-II-Markland and Tobin, 2004) to assess autonomous motivation (intrinsic and identified), controlled motivation (introjected and external) and amotivation towards physical education. Participants responded to each of the twenty items on a five point Likert Scale, ranging from 1 (not true for me) to 5 (very true for me). All items started with 'I put effort into physical education...' followed by items which reflected the SDT categories: intrinsic motivation (e.g. "because this PE class is fun"), identified regulation (e.g. "because it is personally important to me"), introjected regulation (e.g. "because I would feel guilty if I didn't"), external regulation (e.g. "because it's the only way to please others") and amotivation (e.g. "I don't see the point of this PE class"). Each subscale consisted of 4 items, and internal consistencies were good for intrinsic motivation $(\alpha=.80)$ and identified regulation $(\alpha=.70)$, while being moderate for introjected $(\alpha=.63)$ and good for external regulation $(\alpha=.82)$. In the current study, items were then summed into autonomous motivation ( $\alpha=.86)$, controlled motivation $(\alpha=.72)$ and amotivation $(\alpha=.84)$. A

higher order CFA fitted the data well: $\chi^{2}(163)=424.95, \mathrm{p}<.001, \mathrm{RMSEA}=.05, \mathrm{CFI}=.91$, $\operatorname{SRMR}=.08$, hereby supporting the use of composite scores ${ }^{1}$.

\section{Body Satisfaction in Physical Education}

To assess state body satisfaction during physical education, pupils completed the Body Image States Scale (BISS) (Cash et al., 2002) during their physical education lesson. The BISS measures state variations in affective body image as a result of temporal fluctuations and is sensitive to positive and negative contextual variations (Cash et al., 2002). This state assessment of body satisfaction is important given that physical education presents activating events that may fuel information processing in relation to the self-evaluation of appearance (Kerner et al., 2018). The BISS is a six item scale, presented on a 9 point Likert scale. It is used to assess an individual's affect and evaluation of their physical appearance at

\footnotetext{
${ }^{1}$ Note. A five-factor model equally fitted the data equally well $\chi^{2}(160)=333.84, p<.001$, RMSEA $=.05, \mathrm{CFI}=.94, \mathrm{SRMR}=.06$. We did not have any theoretical reasons to expect different results for the specific sub-regulations and therefore relied on the composite scores of autonomous and controlled motivation as well as amotivation.
} 
one particular moment in time. Pupils were asked to respond to the question in the context of their current unit of physical education. The stem preceding each item read 'During your current activity within physical education...'. The six items on the scale reflect satisfaction with overall physical appearance, (e.g. I feel satisfied with my physical appearance), satisfaction with body shape and size (e.g. I feel satisfied with my body shape and size), satisfaction with weight (e.g. I feel satisfied with my weight), feelings of physical attractiveness (e.g. I feel physically attractive), feelings about ones looks relative to others (e.g. I feel much better about my looks than I usually feel) and, finally, evaluation of appearance in relation to the average person (e.g. I feel much better than the average person looks). Three items were reverse scored and the questionnaire was summed and divided by six, with a score of 1 representing dissatisfaction, a score of 5 being neither satisfied nor dissatisfied and a score of 9 being satisfied. The BISS has acceptable convergent validity with other measure of trait body image within college age students (Cash et al., 2002). Moreover, construct validity of the scale has been established in adults (Cash et al., 2002). Adapted versions of the BISS have been previously used with excellent internal reliability in adolescent girls (Bell, Lawton and Dittmar, 2007). The alpha coefficient associated with the Body Image State Scale in the current study was 0.77.

\section{Perceived Sport Promoting Role of Physical Education}

The measurement used by Haerens et al., (2010) was employed to assess the degree to which physical education classes stimulate pupils to engage in sports activities outside of school. Pupils responded to one item which read 'physical education classes stimulate me to also engage in sport activities outside of school'. They responded to this item on a 5 point Likert scale ranging from 0 (not true for me) to 4 (totally true for me).

\section{Data Analysis}

Descriptive statistics, internal reliability coefficients (Cronbach's alpha) and correlation coefficients are presented in Table 1. Based upon Nunnally's (1978) criterion of .70 all Cronbach alpha values obtained were deemed acceptable. We relied on descriptive analyses to answer our first research question, and calculated the percentage of pupils who experienced the physical education lesson had stimulated them to engage in sport activities in leisure time. Given the nested structure of the data with 506 pupils nested into 37 physical education classes, we used multilevel regression analyses in MLwin to examine sex differences in each of the study variables (Table 2).

Tables 1 and 2 about here

Next, we estimated a multilevel path model using Mplus version 7.4 to address our main research questions. Although no specific hypotheses were made at the classroom level, we opted for the multilevel analyses to control for the shared variances of students' responses due to classroom membership. After controlling for gender differences, we examined in a single multilevel path model to what extent body satisfaction related to the sport promoting role of physical education, and whether autonomous motivation, controlled motivation, and amotivation mediated this relation. Body satisfaction was entered as a group-mean centred predictor (i.e., each students' score was entered as the relative score compared to the mean 
scores of his or her class), while the gender covariate was entered uncentred ( $0=$ boys; $1=$ girls). Initially all the slopes (i.e., relations) were estimated as randomly varying, but analyses showed that there was no statistically significant variation in the relations from class to class. As such, all slopes were fixed in the final model.

\section{Results}

Descriptive results as well as correlations between all variables are reported in Table 1. Table 2 reports differences between boys and girls for each of the study variables.

\section{Aim 1. Perceived sport promoting role of physical education}

An average score of $2.12( \pm 1.13)$, on a five point Likert scale ranging from $0-4$ was calculated for the degree to which pupils experienced that physical education had stimulated them towards sports participation, suggesting pupils were just above moderately stimulated by physical education to engage in sport activities outside of school. Boys reported significantly higher scores $(2.47 \pm 1.04)$ than girls $(1.80 \pm 1.11), \beta=0.67 \mathrm{SE}=0.13, \chi^{2}$ $(1)=21.72, p<0.001)$. The data showed that 27.1 percent of the participants felt that physical education did not stimulate them to engage in sports activities outside of school (scores of 0 and 1 ). An average score (score 2 ) was indicated by 35.4 percent of the participants. Almost 40\% (i.e. 37.6\%) of the pupils reported a score of 3 or 4 , suggesting that these groups of pupils feel that physical education did stimulate them to engage in sports activities outside of school.

\section{Aim 2. Relationships between state body satisfaction and the perceived sport promoting role of physical education}

Pupils reported more positively on the perceived sports promoting role of physical education item when they reported higher levels of state body satisfaction $(B=0.19$, $\mathrm{SE}=0.05 ; \beta=0.22, p<0.01)$. This relationship was significant for girls $(B=0.26, S E=0.05, Z=4.85$, $p<.001, \beta=.30$ ) but not so for boys ( $B=0.20, \mathrm{SE}=0.07, \mathrm{Z}=1.74, p=.07, \beta=.14)$.

\section{Aim 3. Mediating role of autonomous motivation, controlled motivation and amotivation in the relationships between state body satisfaction and the perceived sport promoting role of physical education}

In relation to our third research question, the hypothesised model, shown in Figure 1, yielded an acceptable fit $\chi^{2}(13)=29.83, p<.01, \mathrm{CFI}=.965, \mathrm{TLI}=.932$, SRMR (within) $=.025$. As can be seen in Figure 1, body satisfaction related positively to autonomous motivation, which in turn was positively associated with sport promotion. The opposite pattern was found for amotivation, with negative relations from body satisfaction to amotivation and from amotivation to sport promotion. Controlled motivation was not related either to body satisfaction or sport participation. A test of indirect effects showed that body dissatisfaction was positively and significantly related to sport participation by means of autonomous motivation $(b=0.10, S E=0.03, z=3.73, p<.01)$ but not by means of amotivation $(b=0.01$, $S E=0.01, z=1.35, p=.18)$. 
Figure 1 about here

Given the identified sex differences (see Table 2) we further examined the same path model shown in Figure 1, separately for boys (Figure 1, second coefficient) and for girls (Figure 1, third coefficient). For both groups, the path linking body satisfaction with autonomous motivation and the latter with sport participation was statistically significant. A test of indirect effects revealed however that the indirect association was marginally significant for boys $(b=0.06, S E=0.03, z=1.82, p=.068)$, though it continued to be significant, and positive, among girls $(b=0.14, S E=0.04, z=3.55, p<.01)$. Further, unlike the path analysis that include the whole sample, and that of girls, the path analysis for boys showed no statistically significant association between body satisfaction and amotivation. Also, in contrast to the analysis that involved the whole sample, the path linking amotivation with sport promotion was nonsignificant for both of the two groups.

\section{Discussion}

Given the potential role that physical education can play in the promotion of sports participation among adolescents (Shephard and Trudeau, 2000), the first aim of the study was to explore the extent to which pupils perceived physical education stimulated them to engage in sport activities outside of school. Approximately, $38 \%$ of pupils reported that physical education had stimulated them to engage in sports activities outside of school, compared to $27 \%$ that reported negative responses. The average score of 2.12 suggests that pupils were just above moderately stimulated by physical education to engage in sports activities outside of school. This is encouraging as adolescents at the age of 13 are at risk of drop out from sports (Zimmermann-Sloutskis et al., 2010), and physical education lessons may thus have a positive role to play. These findings were more positive than those previously reported by Haerens et al., (2010). In a retrospective study, they found that only $18 \%$ of the questioned university students agreed that physical education stimulated them to engage in sports activities outside school when looking back at their past physical education experiences. However, these differences in findings could be a result of the recall study design used.

We also found significant sex differences in the sport promoting role of physical education, with boys being more likely to report that physical education encouraged them to engage in sports activities outside of school, when compared to girls. These differences can be supported by evidence which suggests girls struggle to identify the purpose of physical education (Flintoff and Scraton, 2001) and experience less enjoyment in physical education (Cairney et al., 2012). Thus, it could be suggested that boys perceive physical education as more interesting. This was also confirmed in the current study as boys were more autonomously motivated for physical education when compared to girls. Furthermore, boys were more satisfied with their bodies in physical education, which reflects suggestions that girls are at a greater risk of body image concerns than boys (Bucchianeri et al., 2013).

Most central to the current article is the question which physical education related factors can explain why pupils are more or less positive about physical educations' sports promoting role, so that pedagogical approaches can be devised to work on these factors. As physical education lessons represent one of the few school subjects in which the body is a 
focus of curricular outcomes, we focused on the role of state body satisfaction in the current study. In physical education, the body is judged for physical ability, and is situated in a space that provides the potential opportunity for social comparisons and body judgements. As such, pupils' state body satisfaction may relate to how they experience physical education lessons (Kerner et al., 2018). In the current study, we found that pupils with higher state body satisfaction were more likely to report that physical education stimulated them to engage in sports activities outside of school. This aligns with the findings of Neumark-Sztainer et al., (2004), who showed that adolescent boys with a high body satisfaction engaged in significantly more physical activity and significantly less sedentary behaviours than those with low body satisfaction. Moreover, the findings also parallel outcomes that suggest body image plays an important role in moderate to vigorous physical activity in 14-16 year olds (Kantanista et al., 2015) and has an indirect influence on lesson time physical activity (Bevans et al., 2010).

To design effective pedagogies that address state body satisfaction, it is important to understand the mechanisms that explain why body satisfaction relates to the perceived sport promoting role of physical education. In this study, we used self-determination theory to examine whether motivational processes can explain why state body satisfaction in physical education may be of influence, extending prior research focusing on social physique anxiety in relation to adolescents' physical activity levels (e.g. Cox et al., 2011). The adoption of a state body image perspective provides important new insights into the relationship from a positive body image perspective. The approach adopted here aligns with the current focus on the appreciation of the body in the body image literature as opposed to the negative body image approach often seen in social physique anxiety research (Tylka and Wood-Barcalow, 2015)

Pupils who experienced lower state body satisfaction in physical education were less likely to be autonomously motivated and more likely to be amotivated towards physical education. This is consistent with the results of research in the USA that has explored the relationship between social physique anxiety and motivation for physical education, in which lower social physique anxiety was associated with greater autonomous motivation and lower amotivation (Cox et al., 2011). Yet, while previous studies have suggested that when individuals experience more concern about their bodies, they may be more likely to internalise pressure to be active, leading to more controlled forms of motivation (Brunet and Sabiston, 2009), this was not confirmed in our study. State body satisfaction in physical education was unrelated to controlled motivation and introjected regulation.

The findings of the current study are consistent with other research which has shown that autonomous motivation mediates the relationship between social physique anxiety and exercise behaviour (Gillison et al., 2006) and physical activity intentions (Sicillia et al., 2016). This suggests that when pupils are satisfied with their bodies in physical education, they are more likely to value and enjoy the activity and subsequently engage in sports activities in their leisure time. These processes hold true for both boys and girls. It appears that lower body satisfaction goes hand in hand with pupils feeling aloof and incapable of reaching the goals (e.g. i.e. amotivation) in physical education. Pupils who display a lack of motivation also more strongly indicated that physical education did not stimulate them pupils to reengage in sports outside school. Yet indirect relations from body satisfaction to sport 
promotion through amotivation were not significant. So amotivation did not account for the relationship between body satisfaction and the sport promoting role of physical education, neither for boys nor for girls. Moreover, neither external or introjected regulation mediated the relationship between body satisfaction and the sport promoting role of $P E$, neither in boys nor in girls.

\section{Practical implications}

,Given sex differences in state body satisfaction, motivation and the sports promoting role of physical education found in the current study, which show less favourable results among girls, physical education teachers require strategies to make physical education more meaningful and enjoyable for girls. This might involve the use of activist approaches to working with girls (Oliver and Kirk, 2016) or the implementation of curricular practices that actively involve girls in curriculum negotiation (Enright and O'Sullivan, 2010). Other effective pedagogical strategies to promote girls' participation, such as inclusive practices that focus on cooperation and collaboration have been advocated elsewhere (Usher et al., 2016).

Findings suggest that state body satisfaction has a significant relationship to motivational outcomes and sports participation outside of school. Although this study was a cross sectional design it adds to an evidence base that highlights the importance of feeling content with the body in physical education (e.g. Carmona et al., 2015). In order to inform practice, future work should explore how physical education teachers can practically encourage body satisfaction within the lesson.

\section{Limitations and Future Directions}

In order to explore further the nature of the relationship between state body satisfaction, motivation and perceived sport participation, longitudinal and experimental studies are needed. The current study was cross-sectional in nature, therefore causality for the different associations found cannot be established. This is important as motivation has also been considered as an antecedent rather than a consequence of body image outcomes (e.g. Thogerson-Ntoumani and Ntoumanis, 2006). When motivation is considered as an antecedent of body image, it is suggested that if exercise is regulated through autonomous means (i.e. individuals exercise through enjoyment), individuals are less likely to be concerned with how others perceive their bodies (Thogerson-Ntoumani and Ntoumanis, 2006).

Experimental and longitudinal studies would also allow to gain further insight into the role of contextual variables (e.g. classroom factors) that may impact on state body satisfaction in physical education. As the results suggest that there are between class differences in the perceived sport promoting role of physical education scores, future research might usefully explore how classroom factors contribute to this between class variance. Future studies could also look at teacher variables. The work of Carmona et al., (2015) for example has identified how physical education teachers can influence the behavioural manifestations of body image disturbance. Future work can also explore the role of individual factors such as experienced need satisfaction in the relationship between body satisfaction and sports 
promotion. For example, it has been suggested elsewhere that body related factors may influence motivational regulation by compromising need satisfaction (Gillison et al., 2011).

In relation to the measurement approaches, a measure of motivation that captures all six motivational regulations, and the development of contextual body satisfaction tools, could extend the current study. Furthermore, in line with the recommendations from Haerens et al., (2010) a more comprehensive measure of sports promotion would be advantageous. In this respect, the inclusion of a measure of autonomous motivation for general sports and physical activity could be of additional value (see Hagger and Chatzisarantis, 2012 for an example).

Finally, future research could also incorporate objective measures of physical activity in order to explore the extent to which adolescents' perceptions of physical education stimulate them to engage in sports activities outside of school correlates with actual leisure time physical activity.

\section{Conclusion}

To our knowledge, this is the first study that has identified that when pupils feel more comfortable and satisfied with their bodies in physical education, they seem to value and enjoy physical lessons more, and this more positive experience stimulates them to reengage in sport outside of school. These findings suggest that physical education programmes aimed at increasing sports participation in adolescents should focus on creating a class environment that promotes state body satisfaction. 


\section{References}

Aelterman N, Vansteenkiste M, Van Keer H, Van den Berge L, De Meyer J and Haerens L (2012) Students' objectively measured physical activity levels and engagement as a function of between-class and between-student differences in motivation toward physical education. Journal of Sport and Exercise Psychology 34 (4): 457-480.

Bevans K, Fitzpatrick LA, Sanchez B and Forrest CB (2010) Individual and instructional determinants of student engagement in physical education. Journal of Teaching in Physical Education 29: 399-416.

Brunet J and Sabiston C M (2009) Examining the relationship between social physique anxiety and physic al activity: a self-determination perspective. Psychology of Sport and Exercise 10: 329:335.

Bucchianeri MM, Arikian AJ, Hannan PJ, Eisenberg MJ and Neumark-Sztainer D (2013). Body dissatisfaction from adolescence to young adulthood: findings from a 10 year longitudinal study. Body Image 10 (1): 1-7.

Cairney J, Kwan MYW, Veldulzen S, Hay J, Bray SR and Faught BE (2012) Gender, perceived competence and the enjoyment of physical education in children: a longitudinal examination. International Journal of Behavioral Nutrition and Physical Activity 9: 26.

Carmona J, Tornero-Quiñones I, Sierra-Robles-A (2015) Body image avoidance behaviors in adolescence: A multilevel analysis of contextual effects associated with the physical education class. Psychology of Sport and Exercise 16 (3): 70-78

Cash TF, Fleming EC, Alindogan J, Steadman L and Whitehead A (2002) Beyond Body Image as a Trait: The Development and Validation of the Body Image States Scale. Eating Disorders: The Journal of Treatment and Prevention 10 (2): 103-113.

Chatzisarantis NLD and Hagger MS (2009) 'Effects of an intervention based on Selfdetermination theory on self-reported leisure-time physical activity participation', Psychology and Health 24: 29-48.

Corder K, Sharp SJ, Atkin AJ, Griffin SJ, Jones AP, Ekelund U and van Sluijs EM (2015) Change in objectively measured physical activity during the transition to adolescence. British Journal of Sports Medicine 49(11):730-6.

Cox AE, Ullrich-French S, Madonia J and Witty K (2011) Social physique anxiety in physical education: Social contextual factors and links to motivation and behaviour. Psychology of Sport and Exercise 12 (5): 555-562.

Deci EL and Ryan R M (1985) Intrinsic motivation and self-determination in human behavior. New York: Plenum.

Deci E L and Ryan RM (2000) The "what" and "why" of goal pursuits: Human needs and the self-determination of behavior. Psychological Inquiry 11 (4): 227-268.

Deci EL and Ryan RM (2012) Motivation, personality, and development within embedded social contexts: An overview of self-determination theory. In R. M. Ryan (Ed.), Oxford handbook of human motivation (pp. 85-107). Oxford, UK: Oxford University Press

Duncan MJ, Al-Nakeeb Y, Nevill A and Jones MV (2004) Body image and physical activity and British secondary school children. European Physical Education Review 10 (3): 243260.

Ekelund U, Tomkinson G and Armstrong N (2011) What proportions of youth are physically active? Measurement issues, levels and recent time trends. British Journal of Sports Medicine, 45 (11): 859-865. 
Enright E and O'Sullivan M (2010)' Can I do it in my pyjamas?' Negotiating a physical education curriculum with teenage girls. European Physical Education Review 16 (3): 202-233.

Flintoff A and Scraton S (2001) Stepping into active leisure? Young women's perceptions of active lifestyles and their experiences of school physical education. Sport, Education and Society 6 (1): 5-21.

Gillison FB, Standage M and Skevington SM (2006). Relationships among adolescents' weight perceptions, exercise goals, exercise motivation, quality of life and leisure-time exercise behaviour: a self-determination theory approach. Health Education Research 21: 836-847.

Gillison FB, Standage M and Skevington SM (2011). Motivation and body-related factors as discriminators of change in adolescents' exercise behaviour profiles. Journal of Adolescent Health 48 (1): 44-51.

Haerens L, Kirk D, Cardon G, De Bourdeaudhuij I and Vansteenkiste M. (2010) The quality and quantity of motivation for secondary school physical education and its relationship to the adoption of a physically active lifestyle among university students. European Physical Education Review 16(2): 117-139.

Hagger MS, Chatzisarantis NL, Hein V, Pihu M, Soós I, Karsai I, Lintunen T and Leemans S. (2009). Teacher, peer, and parent autonomy support in physical education and leisuretime physical activity: A trans-contextual model of motivation in four cultures. Psychology and Health, 24: 689-711.

Hagger MS and Chatzisarantis N L (2012). Transferring motivation from educational to extramural contexts: A review of the trans-contextual model. European Journal of Psychology of Education 27: 195-212.

Hart EA, Leary MR and Rejeski J (1989) The measurement of social physique anxiety. Journal of Sport and Exercise Psychology 11: 94-104.

Hox, J. (2010) Multilevel analysis: Techniques and applications (2nd ed.). New York: Routledge

Janssen I I and LeBlanc AG. (2010) Systematic review of the health benefits of physical activity and fitness in school-age children and youth. International Journal of Behavioural Nutrition and Physical Activity 7 (40):1-16.

Kantanista A, Osinski W, Borowiec J, Tomczak M and Krol-Zielinska M. (2015) Body image, $\mathrm{BMI}$ and physical activity in girls and boys aged 14-16 years. Body Image 15: 40-43.

Kerner C, Haerens L, and Kirk D (2018) Understanding body image in physical education: Current knowledge and future directions. European Physical Education Review, 24 (2):255-265.

Markland D and Tobin V (2004) A modification to the Behavioural Regulation in Exercise Questionnaire to include an assessment of amotivation. Journal of Sport and Exercise Psychology 26: 191-196.

Neumark-Sztainer D, Goedeb C, Story M and Wall M (2004) Associations between body satisfaction and physical activity in adolescents: Implications for programs aimed at preventing a braod spectrum of weight-related disorders. Eating Disorders 12: 125137.

Neumark-Sztainer D, Paxton SJ, Hannan PJ, Stat M, Haines J and Story M. (2006) Does body satisfaction matter? Five year longitudinal associations between body satisfaction and health behaviours in adolescent males and females. Journal of Adolescent Health 39: 244-251. 
Neumark-Sztainer D, Story M, Hannan PJ, Tharp T and Rex J (2003) Factors associated with changes in physical activity: a cohort study of inactive girls. Archieves of Pediatrics and Adolescent Medicine 157 (8): 803-810.

Nunnally J C (1978) Psychometric theory, 2nd ed. New York: McGraw-Hill.

Oliver K and Kirk D (2016) Towards and activist approach to research and advocacy for girls and physical education. Physical Education and Sport Pedagogy 21(3): 313-327.

Reeve J and Jang $\mathrm{H}$ (2006) What teachers say and do to support students' autonomy during a learning activity. Journal of Educational Psychology 98: 209-218.

Rote AE, Swartz AM and Klos LA (2013) Associations between lifestyle physical activity and body image attitudes among women. Womens Health 53 (3): 282-297.

Ryan R M and Deci E L (2007) Active human nature: Self-determination theory and the promotion and maintenance of sport, exercise, and health. In M. S. Hagger and N. L. D. Chatzisarantis (Eds.), Intrinsic motivation and self-determination in exercise and sport (pp. 1-19). Champaign, IL: Human Kinetics.

Sanchez-Olivia D, Sanchez-Miguel PA, Leo FM, Kinnafick FE, Garcia-Calvo T (2014) Physical Education lessons and physical activity intentions within Spanish secondary schools: A self-determination perspective. Journal of Teaching in Physical Education 33: 232-249.

Shephard RJ and Trudeau F (2000) The legacy of physical education: influences on adult lifestyle. Pediatric Exercise Science, 12, 34-50.

Sicilia A, Saenz-Alvarez P, Gonzalez-Cutre D and Ferriz R (2016) Social physique anxiety and intention to be physically activity: A self-determination theory approach. Research Quarterly for Exercise and Sport, 87 (4) 354-364.

Thøgersen-Ntoumani C and Ntoumanis N (2006) The role of self-determined motivation to the understanding of exercise-related behaviours, cognitions and physical selfevaluations. Journal of Sports Sciences 24: 393-404.

Thompson JK (2004) The (mis)measurement of body image: ten strategies to improve assessment for applied and research purposes. Body Image, 1, 7-14

Tylka TL and Wood-Barcalow NL (2015) What is and what is not positive body image? Conceptual foundations and construct definition. Body Image 14: 118-129.

Usher W, Edwards A and Cudmore L (2016) Positioning Australia's contemporary health and physical education curriculum to address poor physical activity participation rates by adolescent girls. Health Education Journal 75 (8): 925-937.

Van den Berghe L, Vansteenkiste M, Cardon G, Kirk D and Haerens L (2014) Research on selfdetermination in physical education: key findings and proposals for future research. Physical Education and Sport Pedagogy 19(1): 97-121.

Wetterhahn KA, Hanson C and Levy CE (2002) Effect of participation in physical activity on body image of amputees. American Journal of Physical Medicine and rehabilitation 81: 194-201.

Zimmermann,-Sloutskis D, Wanner M, Zimmermann E and Martin BW (2010). Physical activity levels and determinants of change in young adults: A longitudinal panel study. The International Journal of Behavioural Nutrition and Physical Activity 7 (2). 
Table 1-Descriptive statistics, Cronbach alpha and correlation coefficients for all variables ( $\mathrm{N}=506)$

\begin{tabular}{|c|c|c|c|c|c|c|c|c|c|c|c|}
\hline Variables & Mean & SD & $\alpha$ & 1 & 2 & 3 & $3 a$ & $3 b$ & 4 & $4 a$ & $4 b$ \\
\hline 1. Sport promotion & 2.12 & 1.13 & - & - & - & - & - & - & - & - & - \\
\hline 2. Body satisfaction & 5.41 & 1.33 & .70 & $.27 * * *$ & - & - & - & - & - & - & - \\
\hline 3. Autonomous motivation & 3.14 & 0.88 & .86 & $.49 * *$ & $.30^{* * *}$ & - & - & - & - & - & - \\
\hline 3a. Intrinsic & 3.29 & 1.02 & .80 & $.46 * * *$ & $.28 * * *$ & $.93 * * *$ & - & - & - & - & - \\
\hline 3b. Identified & 3.11 & .91 & .70 & $.44^{* * *}$ & $.27 * * *$ & $.92^{* * *}$ & $.72 * * *$ & 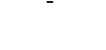 & 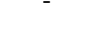 & 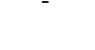 & \\
\hline 4. Controlled motivation & 2.06 & .80 & .72 & $.18^{* * *}$ & -.01 & $.22 * * *$ & $.14^{* *}$ & $.28 * * *$ & - & - & - \\
\hline 4a. Introjected & 2.25 & .89 & .63 & $.23^{* * *}$ & .01 & $.32 * * *$ & $.22^{* * *}$ & $.38^{* * *}$ & $.90 * * *$ & - & - \\
\hline 4b. External & 2.16 & .77 & .82 & $.09 *$ & -.019 & $.08^{* * *}$ & .03 & $.13^{* *}$ & $.89^{* * *}$ & $.60^{* * *}$ & - \\
\hline 5. Amotivation & 1.89 & .98 & .84 & $-.21 * * *$ & $-.13^{* *}$ & $-.35^{* *}$ & $-.37^{* * *}$ & $-.27^{* * *}$ & $.38 * * *$ & $.19 * * *$ & $.51^{* * *}$ \\
\hline
\end{tabular}

${ }^{*} p<0.05,{ }^{* *} p<0.01,{ }^{* * *} p<0.001$ 
Table 2- Mean, standard deviation and multilevel regression analyses to investigate differences in all variables between boys ( $\mathrm{N}=247)$ and girls $(\mathrm{N}=259)$

\begin{tabular}{|c|c|c|c|c|c|c|}
\hline Variables & & Mean & SE & $B_{\text {sex }}(S E)$ & $x^{2}$ & $p$ \\
\hline \multirow[t]{2}{*}{ Sport Promotion } & Male & 2.469 & .070 & $.673(0.098)$ & 46.805 & $<.001$ \\
\hline & Female & 1.796 & .069 & & & \\
\hline \multirow[t]{2}{*}{ Body satisfaction } & Male & 5.720 & .095 & $.617(0.132)$ & 21.716 & $<.001$ \\
\hline & Female & 5.102 & .093 & & & \\
\hline \multirow[t]{2}{*}{ Autonomous motivation } & Male & 3.426 & .062 & $.445(0.088)$ & 25.986 & $<.001$ \\
\hline & Female & 2.980 & .061 & & & \\
\hline \multirow[t]{2}{*}{ Intrinsic } & Male & 3.537 & .076 & $.480(0.106)$ & 20.614 & $<.001$ \\
\hline & Female & 3.057 & .074 & & & \\
\hline \multirow[t]{2}{*}{ Identified } & Male & 3.316 & .062 & $.409(0.086)$ & 22.427 & $<.001$ \\
\hline & Female & 2.907 & .060 & & & \\
\hline \multirow[t]{2}{*}{ Controlled Motivation } & Male & 2.237 & .072 & $.307(0.101)$ & 9.295 & .002 \\
\hline & Female & 1.929 & .071 & & & \\
\hline \multirow[t]{2}{*}{ Introjected } & Male & 2.398 & .070 & $.265(0.098)$ & 7.397 & .007 \\
\hline & Female & 2.132 & .069 & & & \\
\hline \multirow[t]{2}{*}{ External } & Male & 2.067 & .081 & $.353(0.113)$ & 9.749 & .002 \\
\hline & Female & 1.715 & .080 & & & \\
\hline \multirow[t]{2}{*}{ Amotivation } & Male & 1.921 & .080 & $.020(0.112)$ & .031 & .860 \\
\hline & Female & 1.901 & .079 & & & \\
\hline
\end{tabular}




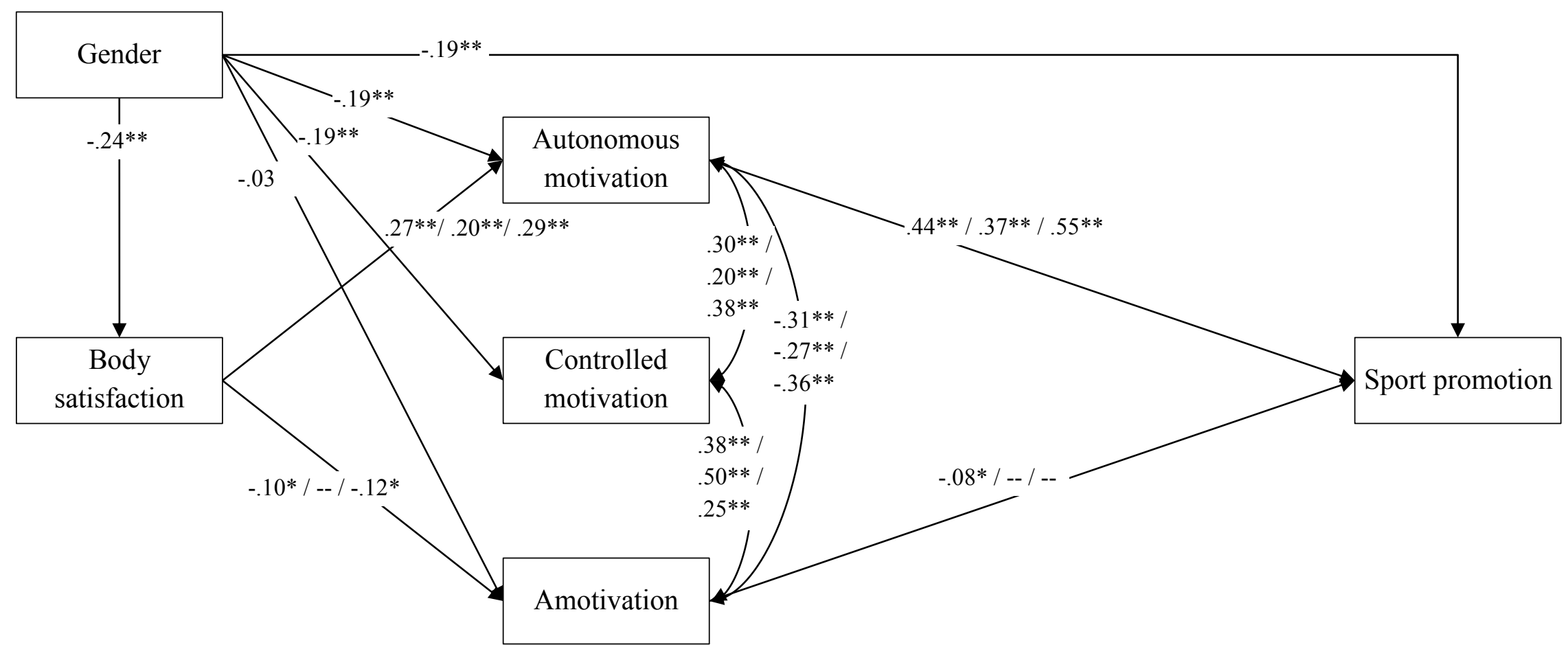

Figure 1. The relationships between Body satisfaction, autonomous motivation, controlled motivation, sport promotion and gender. Note. ${ }^{*} p<.05 . * * p .01$. Best fitting model for the full sample after controlling for gender (first coefficient), for boys only (second coefficient) and for girls only (third coefficient). All paths were standardised; all the slopes were fixed as preliminary analyses showed no statistically significant variation in the slopes across the classes.

Supplementary analyses showed that a direct path linking body satisfaction with sport promotion would have been marginally significant $(b$ $=0.09, S E=0.05, z=1.97, p=.048, \beta=.10)$. In that revised model all the other paths, including the indirect path linking body satisfaction with sport promotion through autonomous motivation, would have remained unchanged. 